\title{
FACTORS AFFECTING REFRIGERATOR-FREEZERS ENERGY CONSUMPTION
}

\author{
R. Saidur*, H.H. Masjuki, T.M.I. Mahlia \\ Department of Mechanical Engineering, University of Malaya \\ 50603 Kuala Lumpur, Malaysia \\ A.R. Nasrudin \\ Department of Electrical Engineering, University of Malaya, \\ 50603 Kuala Lumpur, Malaysia
}

Received 20 May 2002, Accepted 13 July 2002

\begin{abstract}
Two frost-free household refrigerator-freezers, one with 492 liter capacity and one with 4601 liter capacity were tested in the laboratory to determine the sensitivity of several variables those influence refrigerator-freezers energy consumption greatly. The effects of single variables such as room temperature, thermostat setting positions, and door openings on the energy consumption were investigated. Using Response Surface Methodology (RSM), a mathematical model has been developed to investigate the combined effect of room temperature, thermostat setting positions, and door opening on the energy consumption of refrigerator-freezers. From the mathematical model, it has been observed that room-temperature has the highest effect on the energy consumption followed by the thermostat setting position. The door opening has lowest effect on the energy consumption. More detailed tests were performed under different room temperature, thermostat setting positions, and door opening conditions and presented in this paper.
\end{abstract}

Keywords : Door Opening; Energy; Refrigerator; Temperature; Thermostat Setting.

\section{NOMENCLATURE}

$\begin{array}{ll}b: & \text { Constant } \\ \beta: & \text { Matrix of the parameter estimates } \\ D_{d} / d_{o}: & \text { Door opening } \\ E_{A}: & \text { Energy consumption by model A }(\mathrm{Wh} / \text { day }) \\ E_{B}: & \text { Energy consumption by model } \mathrm{B}(\mathrm{Wh} / \text { day }) \\ T_{A \_f f:} & \text { Fresh food temperature for model } \mathrm{A}\left({ }^{\circ} \mathrm{C}\right)\end{array}$

*Corresponding author - e-mail: saidur73@hotmail.com, Fax: +603-79675317, Tel: +603-79674462 


$\begin{array}{ll}T_{A_{-}} f z: & \text { Freezer temperature for model A }\left({ }^{\circ} \mathrm{C}\right) \\ T_{B_{-}} f f: & \text { Fresh food temperature for model B }\left({ }^{\circ} \mathrm{C}\right) \\ T_{B_{-}} f z: & \text { Freezer temperature for model B }\left({ }^{\circ} \mathrm{C}\right) \\ T_{r} / t_{r}: & \text { Room temperature }\left({ }^{\circ} \mathrm{C}\right) \\ T_{s} / t_{s}: & \text { Thermostat setting position } \\ x: & \text { Matrix of independent variables } \\ x^{T}: & \text { Transpose of } x \\ \left(x^{T} x\right)^{-1}: & \text { Inverse of }\left(x^{T} x\right)\end{array}$

\section{INTRODUCTION}

The residential sector of Malaysia consumes about $20 \%$ of her total electricity. Despite the economic downturn, energy consumption in this sector continues to grow [1]. Refrigerator-freezers are one of the major energy users among the household appliances because this appliance is almost common in every house in Malaysia. One study by Razali et al. [2] shows that about $76 \%$ of houses are equipped with household refrigeratorfreezers in Malaysia. The Asia-Pacific Economic Cooperation (APEC) region produces about 60 million refrigerator-freezers out of 100 million refrigerator-freezers produced in the worldwide each year [3]. This appliance also has to operate for 24 hours continuously in a day compared to air conditioners and washing machines. Therefore, energy consumption by household refrigerator-freezers has recently attracted considerable attention for their efficiency improvement. This efficiency improvement could be established introducing energy efficiency standards to encourage consumers to use units that are more efficient. The energy efficiency standards eventually will eliminate the least efficient products from the market. To reduce the energy consumption of refrigerator-freezers and to design more efficient models, it is important to understand the energy consumption behavior of these devices. In order to do so, refrigeratorfreezers energy test procedure must be established. Keeping this in mind, the parameters effecting greatly on refrigerator-freezers energy consumption have been investigated.

Refrigerator-freezers energy consumption is dependent on room temperature, door opening, thermostat setting position, and relative humidity. Relative humidity has insignificant effect on energy consumption compared to the other factors [4,5]. So, its effect on the energy consumption was not investigated in this study. Using RSM and factorial design of experiment, a first order mathematical model has been developed to observe their combined effect on the energy consumption. RSM is a collection of mathematical and statistical techniques useful for analyzing problem in which several independent variables influence a dependent variable or response and the goal is to optimize the response. Many experiments involve a study of the effect of multiple factors. In such a situation, factorial designs are most efficient tools to investigate their combined effect on a response. In this model, a $2^{3}$ factorial design is used to study the combined effect of room temperature, thermostat setting position, and door opening on energy consumption [6]. The objective of this study is to develop an energy test procedure that is most suited for household refrigerator-freezers in Malaysia. 


\section{MATHEMATICAL MODEL FOR DESIGN OF EXPERIMENT}

If all the variables are assumed measurable, the response surface can be expressed as

$$
y=f\left(x_{1}, x_{2}, x_{3}, \ldots \ldots \ldots x_{k}\right)
$$

The goal is to optimize the response variable $y$. It can be assumed that the independent variables are continuous and controllable by the experimenter with negligible error. The response or dependent variable is assumed a random variable. In order to find a suitable combination of room temperature $\left(x_{1}=\ln t_{r}\right)$, thermostat setting position $\left(x_{2}=\ln t_{s}\right)$, and door opening $\left(x_{3}=\ln d_{o}\right)$, the observed response $\mathrm{y}$ as a function of room temperature, thermostat setting positions, and door opening can be written as

$$
\mathrm{y}=f\left(x_{1}, x_{2}, x_{3}\right)
$$

If the expected response is denoted by $E(y)=\eta$, then the surface represented by $\eta=f\left(x_{1}, x_{2}, x_{3}\right)$ is called a response surface. It is required to find a suitable approximation for the true functional relationship between $y$ and the set of independent variables $x_{i}$ 's. Usually a low order polynomial (first order) in some regions of the independent variables is employed.

The first order model,

$$
y=\beta_{o}+\sum_{i=1}^{k} \beta_{i} x_{i}+\varepsilon
$$

is generally utilized in RSM problems. The $\beta$ parameters of the polynomials are estimated by the method of least squares and $\varepsilon$ is a random error. The details of the solution by this matrix approach are explained in [6].

The matrix approach of solving Eq. (3) has been adopted in the present analysis. $y$ is defined to be an $(n \times 1)$ vector of observations on $y, x$ to be an $(n \times p)$ matrix of independent variables, $\beta$ to be a $(p \times 1)$ vector of parameters to be estimated, and $\varepsilon$ to be an $(n \times 1)$ vector of errors. Eq. (3) can be written in matrix form as

$$
\boldsymbol{y}=\beta \boldsymbol{x}+\varepsilon
$$

The least-squares estimates of $\beta$ is the value $\boldsymbol{b}$ which, when substituted into Eq. (3), minimizes $\varepsilon$ ' $\varepsilon$. The normal Eq. can be expressed as

$$
\left(x^{T} x\right) b=x^{T} y
$$

Where $\beta$ is replaced by $\boldsymbol{b}$ matrix. If $\left(x^{T} x\right)$ is non-singular, the solution of normal Eq. (5) can be written as

$$
b=\left(x^{T} x\right)^{-1} x^{T} y
$$

$\boldsymbol{y}$ is defined to be an $(n \times 1)$ matrix on logarithmic scale, $\boldsymbol{x}$ to be an $(n \times m)$ matrix of independent variables, $\boldsymbol{b}$ to be an $(n \times 1)$. The solution of the matrix can be performed using MATLAB. 


\section{EXPERIMENTAL SET-UP AND INSTRUMENTATION}

The experimental set-up and instrumentation have been explained as below:

\subsection{Experiment with single-variable}

The objective of this experiment is to determine the effect of room temperature, thermostat setting position, and door opening on the energy consumption of two household refrigerator-freezers. Tests were conducted by varying the room temperature, thermostat setting position, and door opening independently. During the experiment while one variable was changed, the other two variables were kept constant.

The room temperature was varied from $15^{\circ} \mathrm{C}$ to $31^{\circ} \mathrm{C}$ in an environmentally controlled chamber located in our laboratory to investigate its effect on the energy consumption. The thermostat setting positions were fixed at the medium setting (position 4) for both of the compartments and the relative humidity was maintained at $60 \% \pm 5 \%$. The tests were conducted without any load in the refrigerator-freezers and without opening the door.

There were seven thermostat setting positions ranging from 1 to 7 for these test units. Thermostat setting was varied by turning the knob to the desired setting position from 1 to 7 in order to investigate the effect of thermostat setting position on the energy consumption. The room temperature was maintained at $26^{\circ} \mathrm{C}$, RH was kept at $60 \% \pm 5 \%$, with the units empty with no door openings.

In a 24-hour period of operation time, the door was opened for the first 16 hours of the experiment. The door opening controls were set in such a way that the door remained open for 12 seconds at an angle of $90^{\circ}$. In order to maintain 20-80 door openings over 16 hours of operation, door closing time was not fixed. Table 1 shows the door opening and closing schedule over these 16 hours. Room temperature and $\mathrm{RH}$ were maintained at $26{ }^{\circ} \mathrm{C}$ and $60 \% \pm 5 \%$ respectively for all door opening tests and the thermostat setting positions were kept at the medium positions (positions 4) for both of the compartment.

Table 1 : Door opening and closing schedule

\begin{tabular}{cccc}
\hline No of opening & $\begin{array}{c}\text { Total run time } \\
\text { (minute) }\end{array}$ & $\begin{array}{c}\text { Closing time } \\
\text { (minute) }\end{array}$ & $\begin{array}{c}\text { Door remains open } \\
\text { (sec) }\end{array}$ \\
\hline 20 & 960 & 48 & 12 \\
30 & 960 & 32 & 12 \\
40 & 960 & 24 & 12 \\
48 & 960 & 20 & 12 \\
60 & 960 & 16 & 12 \\
80 & 960 & 8 & 12 \\
\hline
\end{tabular}


The technical specifications of the two models have been shown in Table 2 .

Table 2: Technical specifications of Model A and Model B

\begin{tabular}{lll}
\hline Specifications & Model A & Model B \\
\hline Freezer capacity (liter) & 142 & 130 \\
Fresh food compartment capacity (liter) & 350 & 330 \\
Power rating (Watts) & 190 & 165 \\
Current Rating (A) & 1.35 & 1.3 \\
Voltage (V) & $220-240$ & 240 \\
Frequency (Hz) & 50 & 50 \\
Defrost system & Frost free & Frost free \\
No of door & 2 & 2 \\
Refrigerant type & $134 \mathrm{a}\left(\mathrm{CF}_{3} \mathrm{CH}_{2} \mathrm{~F}\right)$ & $134 \mathrm{a}\left(\mathrm{CF}_{3} \mathrm{CH}_{2} \mathrm{~F}\right)$ \\
\hline
\end{tabular}

\subsection{Experiment with multi-variable}

This experiment was designed to investigate the combined effect of room temperature, thermostat setting position, and door opening on the energy consumption of the refrigerator-freezers.

\subsubsection{Experimental design and conditions}

A design consisting of 12 experiments has been used to develop the first order model to investigate the combined effect of room temperature, thermostat setting position and door opening on the energy consumption. Eight experiments represent a factorial design, 4 experiments represent repetition to estimate the pure error. The experimental design and conditions for multivariable tests have shown in Table 3. A factorial design of experiment is one in which all levels of a given factor are combined with all levels of every other factor in the experiment. This design is necessary when interaction between the variables are to be investigated. Furthermore, factorial designs allow the effects of a factor to be estimated at several levels of the other factors, giving conclusions that are valid over a range of experimental conditions.

The transforming Eqs. for each of the independent variables can be written as:

$$
x_{1}=\frac{\ln \left(t_{r}\right)-\ln (22)}{\ln (30)-\ln (22)}, x_{2}=\frac{\ln \left(t_{s}\right)-\ln (4)}{\ln (10)-\ln (4)}, x_{3}=\frac{\ln \left(d_{0}\right)-\ln (45)}{\ln (70)-\ln (45)}
$$


Table 3 : Experimental design and coding identification

\begin{tabular}{rcccrrr}
\hline Trial No & \multirow{2}{\mathbf{t}_{\mathbf{r}}}{} & $\mathbf{t}_{\mathbf{s}}$ & $\mathbf{d}_{\mathbf{o}}$ & \multicolumn{3}{c}{ Coding } \\
\cline { 5 - 7 } & $\left({ }^{\mathbf{C}} \mathbf{C}\right)$ & $(\mathbf{N o})$ & $(\mathbf{N o})$ & $\mathbf{x}_{\mathbf{1}}$ & $\mathbf{x}_{\mathbf{2}}$ & $\mathbf{x}_{\mathbf{3}}$ \\
\hline 1 & 16 & 2 & 30 & -1 & -1 & -1 \\
2 & 30 & 2 & 30 & 1 & -1 & -1 \\
3 & 16 & 7 & 30 & -1 & 1 & -1 \\
4 & 30 & 7 & 30 & 1 & 1 & -1 \\
5 & 16 & 2 & 70 & -1 & -1 & 1 \\
6 & 30 & 2 & 70 & 1 & -1 & -1 \\
7 & 16 & 7 & 70 & -1 & 1 & 1 \\
8 & 30 & 7 & 70 & 1 & 1 & 1 \\
9 & 22 & 4 & 45 & 0 & 0 & 0 \\
10 & 22 & 4 & 45 & 0 & 0 & 0 \\
11 & 22 & 4 & 45 & 0 & 0 & 0 \\
12 & 22 & 4 & 45 & 0 & 0 & 0 \\
\hline
\end{tabular}

\subsection{Instrumentation}

A heat pump was used to maintain a steady temperature into the environmentally controlled chamber in order to investigate the effect of room temperature. The temperature variation was controlled using an Omega type temperature controller. The daily energy consumption was measured by digital power meter, which was interfaced with PC. Lab view software was installed into the PC for data storage and analysis.

Instead of opening and closing the refrigerator-freezer manually, an automated dooropening and closing mechanism was designed and fabricated. A steel frame containing an $\mathrm{AC}$ motor and a gearbox were mounted on the top of the refrigerator-freezer. The door-opening process is controlled using the Programmable Logic Controller (PLC). The operating switch, which is an input device, sends signals to the motor to open and close the door. Total run time, opening time, and closing time is inserted into the operating switch and it runs as per the experimental requirement.

\section{RESULTS OF SINGLE VARIABLE EFFECT ON ENERGY CONSUMPTION}

\subsection{Effect of room temperature}

The experimental data in Figure 1 shows that energy consumption increases at an average rate of $141 \mathrm{Wh} /$ day for Model A and $102 \mathrm{Wh} /$ day for Model B for each degree increase in room temperature. From the Figure 1, it is evident that energy consumption increases significantly with the increase in room temperature. 


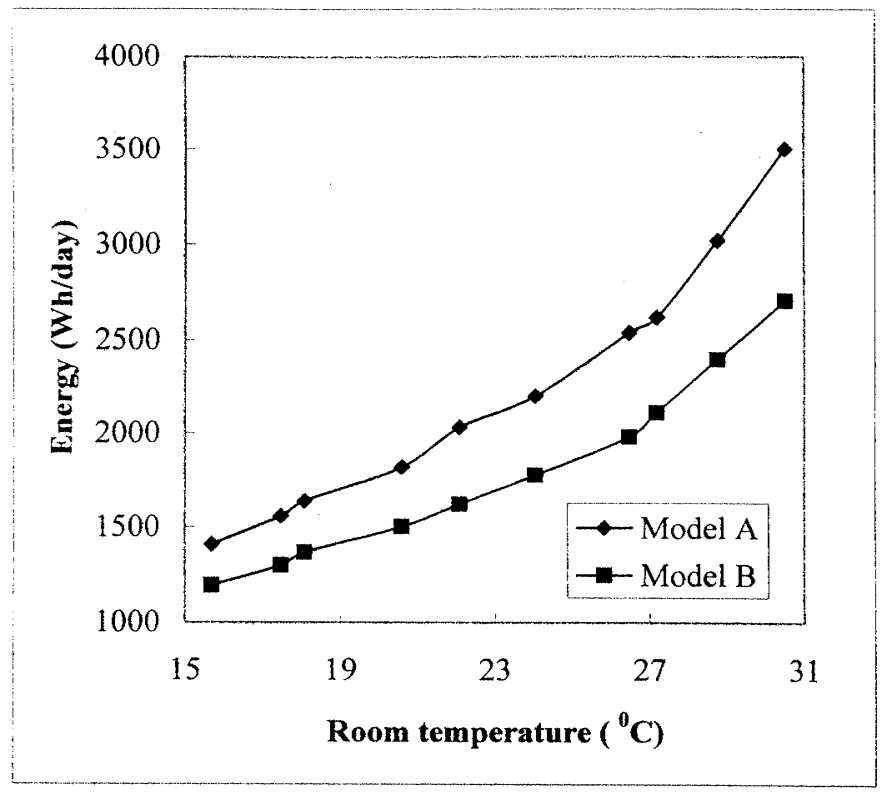

Figure 1: Effect of room temperature on refrigerator-freezers energy consumption

Meier et al. [7] showed that energy consumption increased $120 \mathrm{Wh}$ for each degree increase in temperature. Kao and Kelly [8] conducted the experiment on top mounted freezer unit to investigate the effect of room temperature and reported $120 \mathrm{Wh} /$ day increase in energy consumption for each degree increase in temperature. Grimes et al. [9] found at an average rate of $145 \mathrm{Wh} /$ day increase in energy consumption for each degree increase in temperature. Masjuki et al. [10] conducted an experiment on a Malaysian-produced 150 liter partial auto defrost refrigerator-freezer to investigate the effect of several variables on refrigerator-freezers' energy consumption and reported that $40 \mathrm{Wh} /$ day increase in energy consumption. Bangsal [5] reported that energy consumption increases $39 \mathrm{Wh} /$ day for each degree increase in room temperature for 3701 all-refrigerators.

Discrepancies are due to variation in test units on size, features, design practices, age, year, defrosting system and differences in range of room temperature and so on.

\subsection{Effect of thermostat setting}

The data analysis shows that the energy consumption increases about $11.3 \%$ and $8.8 \%$ for each degree reduction in freezer temperature for models $\mathrm{A}$ and $\mathrm{B}$, respectively. The energy consumption increases $1.363 \mathrm{kWh} /$ day and $1.046 \mathrm{kWh} /$ day for models $\mathrm{A}$ and $\mathrm{B}$, respectively when thermostat was changed from warmest to coldest setting. Figure 2 shows the energy consumption trend with the change in thermostat setting positions for two models. The corresponding fresh food and freezer temperatures are shown in Table 6 for the two models. 




Figure 2 : Effect of TS position on refrigerator-freezers energy consumption

Table 6: Fresh food and freezer temperature at different thermostat setting positions

\begin{tabular}{ccccc}
\hline $\mathbf{T}_{\mathbf{S}}$ & $\mathbf{T}_{\mathbf{A}_{-} \mathbf{f}}$ & $\mathbf{T}_{\beta_{-}} \mathbf{f f}$ & $\mathbf{T}_{\mathbf{A}_{-} \mathbf{f} \mathbf{z}}$ & $\mathbf{T}_{\beta} \mathbf{f} \mathbf{-}$ \\
\hline 1 & 5.84 & 5.76 & -18.1 & -12.5 \\
2 & 4.5 & 3.89 & -18.7 & -13.71 \\
3 & 2.88 & 3.5 & -19.41 & -14.8 \\
4 & 0.25 & 3.35 & -22.3 & -16.13 \\
5 & -1.71 & 1.21 & -23.75 & -16.76 \\
6 & -2.3 & -1.51 & -24.51 & -18.45 \\
7 & -4.5 & -2.1 & -26.13 & -19.6 \\
\hline
\end{tabular}

Just like a house, a refrigerator will use less electricity if its thermostat is re-set to a higher (warmer) temperature. Grimes et al. [9] examined the impact of compartment temperature on energy use on 1977-vintage automatic defrost refrigerator. Energy consumption rose $26 \%$ from the warmest acceptable to the coldest possible settings. A more recent study of nine large, 1993-vintage US refrigerators [11] found $6.5 \%$ increase energy consumption for $1^{\circ} \mathrm{C}$ reduction in freezer temperature. In Ref. [12], it was stated that lowering the freezer temperature by $-15^{\circ} \mathrm{C}$ causes $133 \mathrm{kWh} / \mathrm{yr}$ increase in energy consumption. 


\subsection{Effect of door openings}

In this experiment, it was that energy consumption increases $12.4 \mathrm{Wh}$ and $9 \mathrm{Wh}$ for each door opening for models $\mathrm{A}$ and $\mathrm{B}$, respectively. Figure 3 shows the energy consumption trend with door openings for two models. It has been found that with the increase in number of door openings, energy consumption also increases linearly.

Masjuki et al. investigated the impact of door openings on refrigerator-freezer energy consumption and reported that energy consumption increases $10 \mathrm{Wh} /$ day for each door opening. Parker and Stedman [11] estimated that each door opening causes $9 \mathrm{Wh}$ increase of energy consumption.

When the refrigerator door is opened, warm and moist air exchange with cool air inside the refrigerator cabinet. When the door is closed, a mass of air at room temperature is trapped in the compartment. Heat gain during door openings is due to (i) heat/vapor transfer on the interior surfaces of refrigerator, (ii) bulk air exchange.

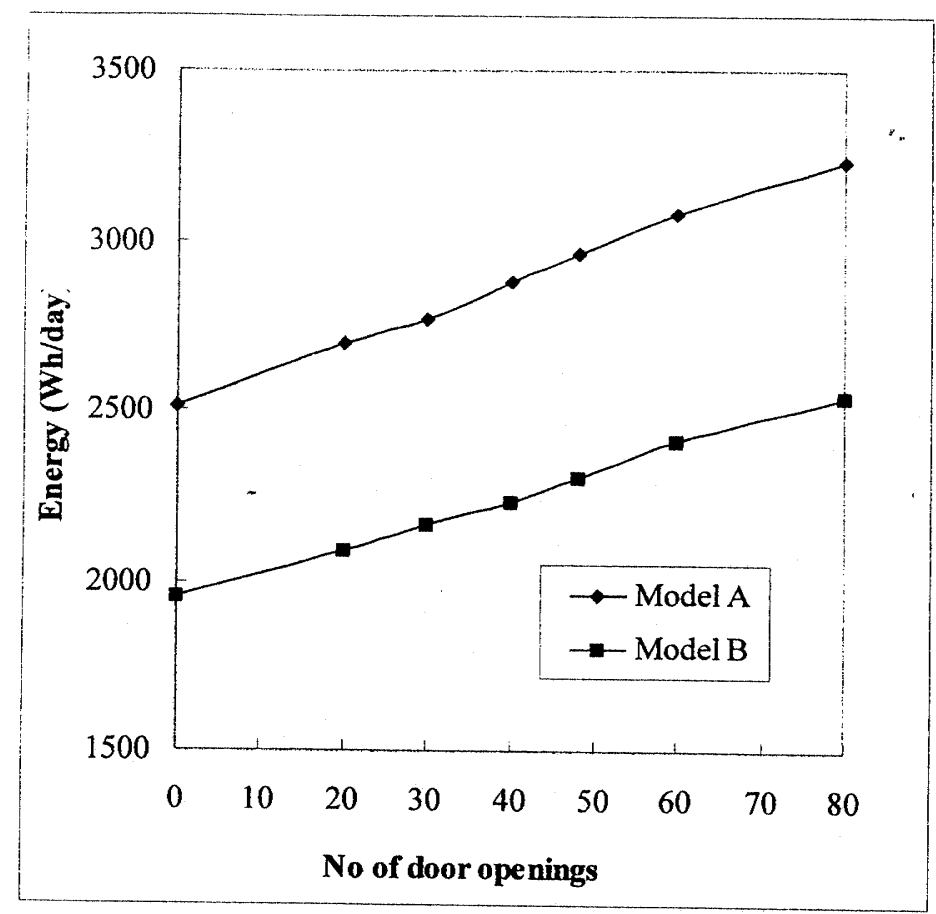

Figure 3 : Effect of door opening on refrigerator-freezers energy consumption

\section{EXPERIMENTAL RESULTS OF MULTI-VARIABLE EFFECT ON ENERGY CONSUMPTION}

From the experimental results shown in Table 4, model Eq. (11) has been developed using Eqs. (3) and (7). The $b$ parameter has calculated and presented in Table 5. 
Table 4 : Experimental results of multi-variables test

\begin{tabular}{ccc}
\hline Trial no & \multicolumn{2}{c}{ Energy consumption $(\mathbf{W h} / \mathbf{d a y})$} \\
\cline { 2 - 3 } & Model A & Model B \\
\hline 1 & 1841 & 1545 \\
2 & 2718 & 2450 \\
3 & 2408 & 2150 \\
4 & 3716 & 3344 \\
5 & 2178 & 1921 \\
6 & 3093 & 2725 \\
7 & 2771 & 2433 \\
8 & 4089 & 3673 \\
9 & 2445 & 2013 \\
10 & 2420 & 2035 \\
11 & 2439 & 2053 \\
12 & 2450 & 2025 \\
\hline
\end{tabular}

Table 5 : Values of constant $b$

\begin{tabular}{ccc}
\hline Value of $\mathbf{b}$ & Model A & Model B \\
\hline $\mathrm{b}_{0}$ & 7.8829 & 7.7342 \\
$\mathrm{~b}_{1}$ & 0.1954 & 0.2164 \\
$\mathrm{~b}_{2}$ & 0.1376 & 0.1554 \\
$\mathrm{~b}_{3}$ & 0.0667 & 0.0761 \\
\hline
\end{tabular}

$$
\begin{aligned}
& \ln E_{A}=5.0201+0.623 \ln t_{r}+0.246 \ln t_{s}+0.151 d_{o} \\
& \text { and } \\
& \ln E_{B}=4.531+0.697 \ln t_{r}+0.278 t_{s}+0.172 \mathrm{~d}_{o}
\end{aligned}
$$

The above Eq. can also be written in the form of energy consumption as a function of room temperature $(\mathrm{tr})$, thermostat setting position $\left(\mathrm{t}_{\mathrm{s}}\right)$, and door opening $\left(\mathrm{d}_{\mathrm{o}}\right)$ as follows:

$$
\begin{aligned}
& E_{A}=151.49 t_{r}^{0.623} t_{s}^{0.246} d_{o}^{0.151} \\
& \text { and } \\
& E_{B}=92.81 t_{r}^{0.697} t_{s}^{0.278} d_{o}^{0.172}
\end{aligned}
$$

\section{CONCLUSION}

The following conclusions could be made from this study:

1. As Malaysia is going to adopt energy efficiency standards and labels for refrigeration appliances, a more realistic test procedure is needed in order to evaluate their energy consumption behavior of these appliances. Refrigerator- 
freezers energy consumption is strongly influenced by room temperature, thermostat setting positions and door openings. To develop an energy test procedure for these appliances, effect of these parameters must be taken into consideration. So, this paper can be considered as experimental support to develop a test standard for household refrigerator-freezers in Malaysia.

2. Ambient temperature has the highest effect on energy consumption followed by thermostat setting position. The door opening has the lowest effect refrigeratorfreezers' energy consumption.

3. The door opening pattern in this study can be considered as more realistic with the actual usage condition that exists in a household environment.

\section{REFERENCES}

1. Anon. Jabatan Bekalang Elektrik dan Gas, Statistics of electricity supply industry in Malaysia. Annual report, Kuala Lumpur: Malaysia, JBEG, 1999.

2. Razali MA, Othaman MN, Sim OF. Residential and commercial electricity consumers in Subang Jaya and Bandar Baru Bangi. Housing and Energy project, Institute for Advanced Studies, University of Malaya, Kuala Lumpur, Malaysia, 1993.

3. Zakaria MY, Farida T. Keynote paper "Forum on energy performance and labeling standards for refrigeration", $27^{\text {th }}$ June, 2000, SIRIM, Grand blue hotel, Malaysia, pp. 1-2.

4. Alissi MS. The effect of ambient temperature, ambient humidity and door openings on household refrigerator energy consumption. MSME thesis, Purdue University, Indiana, 1987.

5. Bansal PK, Energy Efficiency Test Standards for Household Refrigerators. Proceedings of Symposium on Domestic Refrigeration Appliances. 6-8 March 2000, Wellington, New Zealand, pp. 1-14.

6. Montgomery DC. Design and analysis of experiments. $2^{\text {nd }}$ edition, Wiley, New York, 1984.

7. Meier A, Megowan A, Lit B, Pon B. The New York refrigerator monitoring project. Final report, $L B L-33708$, Lawrence Berkeley Laboratory, CA, 1993.

8. Kao JY, Kelly GE. Factors affecting the energy consumption of two refrigerator-freezers. ASHRAE Transaction, 102 (2), 1996, pp. 525-545

9. Grimes JG, William PEM, Shomaker BL. Effect of usage conditions on household refrigerator-freezer and freezer energy consumption. ASHRAE Transaction 1977; 83 (1): 818-28.

10. Masjuki HH, Saidur R, Choudhury IA, Mahlia TMI, Ghani AK, Maleque MA. The applicability of ISO refrigerator-freezer energy test specifications in Malaysia. Paper accepted for publication to ENERGY - The international Journal. Elsevier Science, UK, 2001.

11. Parker DS, Stedman T. Refrigerator replacement in Florida: A case study. Home energy, 10 (1), 1993. pp.20-22.

12. Meier AK. Do refrigerator thermostat setups save energy? Home energy, 11 (3), May/June, 1994, pp. 11. 